\title{
Case Report \\ Bilateral Dorsal Foot Pain in a Young Tennis Player - Managed by Neurodynamic Treatment Techniques
}

Rebecca Nelson

Toby Hall

Keywords: peripheral neuropathic pain

neurodynamic treatment

neural tissue mechanosensitivity.

Professional Qualifications: Rebecca Nelson

M Manip Phty, Post Grad Dip Manip Phty

Toby Hall

MSc, Post Grad Dip Manip Ther, FACP

Current Relevant Appointment

Rebecca Nelson, Director of Physiotherapy, Apex Clinic, Stormont, Belfast BT5 7HD, Northern Ireland, UK

Toby Hall, Adjunct Senior Teaching Fellow, School of Physiotherapy, Curtin Innovation Health Research Institute, Curtin University of Technology, Hayman Road, Bentley, Western Australia

Corresponding Author:

Rebecca Nelson, Apex Clinic, Stormont, Belfast BT5 7HD, Northern Ireland, UK

Tel.: +28 90484153

Fax.: +28 90487218

E-mail address: info@apexclinic.co.uk 


\section{Introduction}

Exercise-related lower limb pain represents one of the most common presentations in sports medicine practice (McCrory et al., 2002). This is usually caused by musculoskeletal overuse injuries but not uncommonly, a neuropathic cause may be suspected (Gallant, 1998; McCrory et al., 2002). In addition to compressive radiculopathy and nerve entrapment, peripheral neuropathic pain mechanisms may contribute to musculoskeletal syndromes commonly seen in sport such as hamstring strains (Kornberg and Lew, 1989) and ankle inversion sprains (Pahor and Toppenberg, 1996).

Various examination procedures have been proposed to assist with the diagnosis of peripheral neuropathic pain (Elvey and Hall, 1997; Shacklock, 2005; Nee and Butler, 2006). Such disorders have been recently sub-categorized (Schafer et al., 2009a; Schafer et al., 2009b) into sensory hypersensitivity (involving predominantly sensitization of the central nervous system), denervation (due to significant fascicular damage) and peripheral nerve sensitization (arising from increased axonal mechanosensitivity). Elvey and Hall (1997) presented a series of physical examination criteria required to be present before a diagnosis of peripheral nerve sensitization (PNS) can be determined.

Neurodynamic treatment techniques have been described to manage pain arising from peripheral nerve disorders (Butler, 2000; Shacklock, 2005). Various studies have reported on the beneficial effects of such treatment (Kornberg and Lew, 1989; Klingman, 1999; George, 2000; Cleland and McRae, 2002; George, 2002; Meyer et al., 2002; Cleland et al., 2004). However, only one of the lower limb studies (Cleland et al., 2004) used the classification system described by Elvey and Hall (1997), so it is uncertain which form of nerve disorder the remaining lower limb studies reported on.

A review of the literature pertaining to neurodynamics revealed that peripheral neuropathic pain has never been documented or addressed in a child. Lumbar disc pathology in children has been suggested to be more common than previously thought (Fairbank et al., 1984; Paajanen et al., 1989; Balague et al., 1995; Kjaer et al., 2005), hence it is possible that peripheral neuropathic pain of spinal origin, may be more prevalent in children than previously recognized.

This case report describes the presentation of an adolescent tennis player with bilateral dorsal foot pain who presented with positive findings of lower extremity PNS which was successfully managed using neurodynamic treatment techniques.

\section{Case History}


A 12 year old male competitive tennis player, who played for 15 hours per week presented to physiotherapy with bilateral dorsal foot pain and occasional stabbing pain in his lower back (Figure 1). The foot pain occurred daily since onset and was often severe in intensity. He reported that the foot pain was functionally restrictive and curtailed his sporting activities, to the extent that he had been sporadically missing tennis training.

The foot pain and infrequent back symptoms started $21 / 2$ years previously, after a go-cart accident in which he suffered a forced lumbar spine flexion injury. Consequent low back pain settled without intervention within one month. However, dorsal foot pain developed becoming severe two months later. The patient consulted a medical practitioner on three occasions and a diagnosis of "growing pains" was given. He changed his tennis trainers without effect. He also attended a physiotherapist elsewhere who diagnosed an overuse injury of both feet and recommended foot orthoses. The patient subsequently consulted a podiatrist who reported normal foot biomechanics and that orthoses were not required. The confusion in the diagnosis prompted the patient to seek a second physiotherapy opinion.

Several aggravating factors for the foot pain were identified including walking (20 minutes), running (5 minutes) and playing tennis (40 minutes). Running on his toes induced the foot pain more quickly. The foot pain reached 8/10 on a visual analogue scale (VAS) within 1 hour of playing tennis. The lower back "stab" was elicited on trunk flexion, especially first thing in the morning. It also occurred with the foot pain when lifting heavy objects and during prolonged sitting in a slouched position. No night pain was reported and there was no spontaneous pain or stimulus-independent pain.

At the time of the initial consultation the patient was taking non-steroidal antiinflammatory medication before playing tennis. He had no prior history of leg or back symptoms. In addition, there were no yellow flags or red flags that would contraindicate neurodynamic treatment (Butler, 2000).

\section{Physical Examination}

In standing, the patient's posture and gait were unremarkable. In contrast he sat with a kyphotic lumbar posture. When asked to run on his toes as a test for 1 minute this reproduced his foot pain bilaterally which he scored as $3 / 10$ on a VAS.

All lumbar active movements were full range and pain-free with the exception of lumbar flexion, which reproduced back and foot pain. Lumbar flexion in standing with the cervical spine pre-positioned in flexion (Hall and Elvey, 1999) increased the intensity of the foot pain but not the back pain. 
The straight leg raise (SLR) test on both sides was limited to 65 degrees but did not produce symptoms. The right and left SLR with plantarflexion/inversion (Slater, 1989; Butler, 2000; Shacklock, 2005) both reproduced the foot pain with onset of pain at approximately 35 degrees and 40 degrees range of SLR respectively. Hip adduction and medial rotation (Breig and Troup, 1979) increased the foot pain during SLR.

The slump test was performed on the right and left with plantarflexion/inversion rather than ankle dorsiflexion (Butler, 2000; Shacklock, 2005). Active knee extension reproduced the foot symptoms with the onset of pain at approximately -40 degrees knee extension on each side. The slump test was determined to be "positive" on both sides as the foot pain diminished with the release of cervical flexion (Nee and Butler, 2006).

Palpation of the muscles and tendons on the dorsal foot was unremarkable. In contrast, gentle palpation of the superficial peroneal nerve trunk on the dorsal foot was significantly painful bilaterally. Resisted muscle testing of the foot and ankle revealed no abnormality. Movement of the ankles and feet was also unremarkable, as was accessory movement testing of the foot and ankle joints (Maitland, 1991).

There were no significant features of central sensitization (sensory hypersensitivity) such as widespread light touch allodynia or thermal allodynia (Hall and Elvey, 2004; Schafer et al., 2009a). In addition, there were no clinical signs of superficial peroneal nerve entrapment, namely pain or anaesthesia over the lateral calf and/or dorsum of the foot with resisted ankle dorsiflexion and eversion (Styf and Korner, 1986; Styf, 1989; Akyuz et al., 2000). Neurological examination of the lower limbs was normal.

Postero-anterior (PA) mobilization of the lumbar spine, both centrally and unilaterally (Maitland et al., 2001) revealed hypomobility and reproduced the patient's lower back stabbing pain at the L2/L3 motion segment.

\section{Working Hypothesis and Differential Diagnosis}

The patient fulfilled the clinical diagnostic criteria according to Elvey and Hall (1997) indicating a PNS disorder (Schafer et al., 2009a). This involved the sciatic nerve and its terminal branch, the superficial peroneal nerve trunk. The anatomical location of sensitization was thought to be the lumbar spine, probably a discogenic cause based on the history and physical examination findings.

The differential diagnoses for the patient's presentation included growing pains, entrapment of the superficial peroneal nerve or a local tissue overuse injury. Growing pains are the most common cause of childhood musculoskeletal pain (Uziel and Hashkes, 2007). This diagnosis is based on a number of clinical characteristics (Uziel and Hashkes, 2007; Evans, 2008). These include: pain 
that appears late in the day or is nocturnal, often wakening the child at night; episodic pain, with pain-free intervals from days to months. These features were not present and this diagnosis eliminated.

Entrapment of the superficial peroneal nerve is a rare occurrence and usually caused by external forces (Hirose and McGarvey, 2004). The fact that the foot pain, accompanied by the lower back "stab" was elicited by heavy lifting and by prolonged sitting in a slouched position was inconsistent with this diagnosis. In addition there were no clinical signs of superficial peroneal nerve entrapment.

An overuse injury of muscle or tendon was considered but eliminated because of a lack of clinical findings which would correlate with this (Brukner and Khan, 2001).

\section{Outcome measures}

There were four outcome measures: the VAS score to quantify worst pain during the previous tennis training session; range of SLR with plantarflexion/inversion at the onset of pain; range of knee extension during slump testing with plantarflexion/inversion; and the VAS score of foot pain after one minute of running on his toes. A summary of the outcome measures recorded on the initial and final physiotherapy sessions is displayed in Table 1.

\section{Treatment}

There were 16 treatment sessions over 12 weeks. The first visit included the initial evaluation, data collection and patient education. Due to the aggravating activities the patient was shown postural correction in sitting and was advised to avoiding heavy lifting and prolonged lumbar flexion. He was also advised to reduce training to three sessions per week (9 hours).

All subsequent sessions included reassessment followed by implementation of the intervention and are displayed in Table 2. On the second session a central PA mobilization of the L2 vertebra failed to influence the outcome measures (Maitland et al., 2001). Consequently, neural mobilization was applied in the form of four sets of 20 repetitions of right SLR to just prior to the onset of pain, with the ankle pre-positioned in plantarflexion/inversion (Butler, 1991; Butler, 2000). Right SLR with plantarflexion/inversion immediately increased in range.

Sessions three to nine focussed on progressive right sided neural mobilization together with a home exercise as an adjunct to the treatment provided in the clinic (Butler, 1991; Butler, 2000). Over this time, the outcome measures steadily improved on the right side only, and by session ten, the right foot was symptomfree. 
Sessions ten to sixteen were aimed at reducing the left foot pain, starting with SLR mobilization. Following two sessions there was no improvement and hence treatment was modified. At this point, unilateral PA pressure on the left, applied to the L2/L3 facet joint was symptom-free in prone. However, this technique administered in a left SLR position with ankle plantarflexion (Klingman, 1999; Butler, 2000) reproduced the lower back stabbing pain. The patient was mobilized unilaterally in this position. On re-assessment, there was an improvement of 10 degrees on range of left SLR with plantarflexion/inversion. Over the following sessions, this treatment technique was progressed by increasing the range of both SLR and plantarflexion.

On Session 17, a review, the patient was symptom-free and was playing tennis at his pre-injury capacity. All outcome measures were pain-free and are summarised in Table 1. When contacted six months later, he had remained symptom-free with unrestricted tennis activity.

\section{Discussion}

This case report suggests that neurodynamic treatment was an effective management strategy for this patient with evidence of lower extremity PNS. It was hypothesised that the patient's condition arose from a lumbar disc injury, with consequent inflammatory reaction of lumbar nerve roots. The clinical reasoning which led to the aforementioned diagnosis will subsequently be discussed.

Lumbar intervertebral disc injury was incriminated in the pathogenesis of the patient's condition due to the nature of the injury and the fact that the symptoms were aggravated by activities/positions which increased the intradiscal pressure, such as bending, heavy lifting and prolonged sitting.

PNS was hypothesised to be the cause of the patient's foot pain. Aggravating factors indicate that the lumbar disorder and the neural tissue dysfunction appear to be related. However, there was no evidence of neurological deficit indicating nerve root compression. It was therefore hypothesised that PNS occurred through inflammation of the lumbar neural structures following the traumatic lumbar disc injury (Bobechko and Hirsch, 1965; McCarron et al., 1987; Saal et al., 1990; Olmarker et al., 1993; Spiliopoulou et al., 1994; Greening, 2004). Schafer et al., (2009a) discussed in detail the pathophysiology of leg pain arising from PNS, secondarily to lumbar disc injury.

Lumbar disc annular tears have been identified in children. Kjaer et al. (2005) used magnetic resonance imaging (MRI) to investigate the prevalence rate of lumbar disc pathology in 43913 year-old children. They reported a $7 \%$ prevalence rate of one or more lumbar annular tears, $10 \%$ of which occurred at the L2/3 level. Discography however, has been demonstrated to be more 
accurate than MRI in detecting annular fissures (Shah et al., 2005) consequently the true prevalence rate may possibly be higher.

The reliability of suitably trained physiotherapists to identify the symptomatic vertebral level during PAIVM testing has been questioned (Maher and Adams, 1994; Binkley et al., 1995; Downey et al., 2003). However there are reports that therapists can accurately diagnose the symptomatic spinal level in the lumbar spine (Phillips and Twomey, 1996; Downey et al., 1999; Schneider et al., 2008). Assuming that the L2/3 spinal level was indeed the segmental origin of the patient's symptoms, the anatomical rationale as to how the L2/3 level caused foot pain is unknown. The sciatic nerve and its terminal branches arise from the $L 4$ to S3 nerve roots. Pathology of the lower lumbar spine would be expected to affect these nerve roots and not the L2/3 level. Anomalous lumbar nerve root anatomy is a possible explanation for how the L2/3 level could cause foot pain. Such anomaly is common (Chotigavanich and Sawangnatra, 1992; Tanaka et al., 2000).

The improvement demonstrated in this case report appears to be beyond that attributable to spontaneous remission. The exact physiological mechanisms by which symptom reduction occurred is entirely speculative (Cleland et al., 2004; Nee and Butler, 2006). There have been a number of hypotheses to explain the positive benefits of neurodynamic treatments (Butler, 2000; Hall and Elvey, 2004; Shacklock, 2005) however scientific evidence is lacking (Cleland et al., 2004). One mechanism may be gradual desensitization of the mechanosensitive lumbar neural structures through modulation of descending inhibitory pathways. Evidence for this is shown in a recent study of a neural mobilization technique in the cervical spine (Sterling et al., 2010).

There are a number of limitations in this study. Firstly, spontaneous recovery may have occurred, however the $21 / 2$ year stable history indicates that this was unlikely. Secondly, activity and postural modification may have been the catalyst for recovery rather than the neurodynamic treatment. Finally, although the findings of this case study support the positive effects of neurodynamic treatment, a cause-and-effect relationship cannot be confirmed.

\section{Conclusion}

This case report suggests the effectiveness of neurodynamic treatment in a child with bilateral foot pain who fulfilled published criteria for PNS. The single case methodology employed in this study however limits statistical generalization of its findings. The presentation of peripheral neuropathic pain in a child is highlighted and demonstrates that this disorder is not confined to the adult population. On the basis of this case report, further studies are warranted to investigate the role of neurodynamics in musculoskeletal pain disorders in children.

\section{References}


Akyuz G, Us O, Turan B, et al. Anterior tarsal tunnel syndrome. Electromyography and Clinical Neurophysiology 2000;40(2):123-128.

Balague F, Skovron ML, Nordin M, Dutoit G, Rer Pol L, Waldburger M. Low back pain in schoolchildren. Spine 1995;20:1265-1270.

Binkley J, Stratford PW, Gill C. Inter-rater reliability of lumbar accessory motion mobility testing. Physical Therapy 1995;75(9):786-795.

Bobechko WP, Hirsch C. Auto-immune response to nucleus pulposus in the rabbit. Journal of Bone and Joint Surgery 1965;47B:574-580.

Breig A, Troup JDG. Biomechanical considerations in the straight leg raising test: cadaveric and clinical studies of the effects of medial hip rotation. Spine 1979;4:242-250.

Brukner P, Khan K. Clinical sports medicine. $2^{\text {nd }}$ ed. New York: The McGraw-Hill Companies; 2001.

Butler DS. Mobilisation of the nervous system. Melbourne, Australia: Churchill Livingstone; 1991.

Butler DS. The sensitive nervous system. Adelaide, Australia: Noigroup Publications; 2000.

Chotigavanich C, Sawangnatra S. Anomalies of the lumbosacral nerve roots: an anatomic investigation. Clinical Orthopaedics and Related Research 1992;278:46-50.

Cleland J, McRae M. Complex regional pain syndrome I: management through the use of vertebral and sympathetic trunk mobilization. Journal of Manual and Manipulative Therapy 2002;10(4):188-199.

Cleland J, Hunt GC, Palmer J. Effectiveness of neural mobilization in the treatment of a patient with lower extremity neurogenic pain: a single case design. Journal of Manual and Manipulative Therapy 2004;12(3):143-152.

Downey BJ, Taylor NF, Niere KR. Manipulative physiotherapists can reliably palpate nominated lumbar spinal levels. Manual Therapy 1999;4(3):151-156.

Downey B, Taylor N, Niere K. Can manipulative physiotherapists agree on which lumbar level to treat based on palpation? Physiotherapy 2003;89(2):74-81. 
Elvey R, Hall T. Neural tissue evaluation and treatment. In: Donatelli R, editor. Physical therapy of the shoulder. $3^{\text {rd }}$ ed. New York: Churchill Livingstone; 1997.p. 131-152.

Evans AM. Growing pains: contemporary knowledge and recommended practice. Journal of Foot and Ankle Research 2008;1(4):1-7. doi:10.1186/1757-1146-1-4 (last accessed $29^{\text {th }}$ September 2009).

Fairbank JCT, Pynset PB, Van Poortyliet JA, Phillips H. Influence of anthropometric factors and joint laxity in the incidence of adolescent back pain. Spine 1984;9:461-464.

Gallant S. Assessing adverse neural tension in athletes. Journal of Sport Rehabilitation 1998;7:128-139.

George SZ. Differential diagnosis and treatment for a patient with lower extremity symptoms. Journal of Orthopaedic and Sports Physical Therapy 2000;30(8):468472.

George SZ. Characteristics of patients with lower extremity symptoms treated with slump stretching: a case series. Journal of Orthopaedic and Sports Physical Therapy 2002;32:391-398.

Greening J. How inflammation and minor nerve injury contribute to pain in nerve root and peripheral neuropathies. In: Boyling JD, Jull GA, editors. Grieve's modern manual therapy: the vertebral column. $3^{\text {rd }}$ ed. Edinburgh: Churchill Livingstone; 2004.p. 205-214.

Hall T, Elvey R. Nerve trunk pain: physical diagnosis and treatment. Manual Therapy 1999;4(2):63-73.

Hall TM, Elvey RL. Management of mechanosensitivity of the nervous system in spinal pain syndromes. In: Boyling JD, Jull GA, editors. Grieve's modern manual therapy: the vertebral column. $3^{\text {rd }}$ ed. Edinburgh: Churchill Livingstone; 2004.p. 413-431.

Hirose CB, McGarvey WC. Peripheral nerve entrapments. Foot and Ankle Clinics of North America 2004;9:255-269.

Kjaer P, Leboeuf-Yde C, Solgaard Sorensen J, Bendix T. An epidemiologic study of MRI and low back pain in 13 year old children. Spine 2005;30(7):798-806.

Klingman RE. The pseudoradicular syndrome: a case report implicating double crush mechanisms in peripheral nerve tissue of the lower extremity. Journal of Manual and Manipulative Therapy 1999;7(2):81-91. 
Kornberg C, Lew $\mathrm{P}$. The effect of stretching neural structures on grade one hamstring injuries. Journal of Orthopaedic and Sports Physical Therapy 1989;10:481-487.

McCarron RF, Wimpee MW, Hudkins PG, Laros GS. The inflammatory effect of nucleus pulposus. A possible element in the pathogenesis of low back pain. Spine 1987;12(8):760-764.

McCrory P, Bell S, Bradshaw C. Nerve entrapments of the lower leg, ankle and foot in sport. Sports Medicine 2002;32(6):371-391.

Maher C, Adams R. Reliability of pain and stiffness assessments in clinical manual lumbar spine examination. Physical Therapy 1994;75:801-811.

Maitland GD. Peripheral manipulation. $3^{\text {rd }}$ ed. London: Butterworth-Heinemann; 1991.

Maitland GD, Hengeveld E, Banks K, English K. Maitland's vertebral manipulation. $6^{\text {th }}$ ed. London: Butterworth-Heinemann; 2001.

Meyer J, Kulig K, Landel R. Differential diagnosis and treatment of subcalcaneal heel pain: a case report. Journal of Orthopaedic and Sports Physical Therapy 2002;32:114-124.

Nee RJ, Butler D. Management of peripheral neuropathic pain: integrating neurobiology, neurodynamics and clinical evidence. Physical Therapy in Sport 2006;7:36-49.

Olmarker K, Rydevik B, Nordberg C. Autologous nucleus pulposus induces neurophysiologic and histologic changes in porcine cauda equina nerve roots. Spine 1993;18:1425-1432.

Paajanen $\mathrm{H}$, Erkintalo M, Kuusela BMT, Dahlstrom S, Kormano M. Magnetic resonance study of disc degeneration in young low-back pain patients. Spine 1989;14:982-985.

Pahor S, Toppenberg R. An investigation of neural tissue involvement in ankle inversion sprains. Manual Therapy 1996;1(4):192-197.

Phillips DR, Twomey LT. A comparison of manual diagnosis established by a unilevel lumbar spinal block procedure. Manual Therapy 1996;2:82-87.

Saal JS, Fransone RC, Dobrow R, et al. High levels of inflammatory phospholipase A2 activity in lumbar disc herniations. Spine 1990;15:674-678. 
Schafer A, Hall T, Briffa K. Classification of low back related leg pain- a proposed patho-mechanism based approach. Manual Therapy 2009a;14:222-230.

Schafer A, Hall T, Ludtke K, Mallwitz J, Briffa NK. Interrater reliability of a new classification system for patients with neural low back related leg pain. Journal of Manual and Manipulative Therapy 2009b;17(2):109-117.

Schneider M, Erhard R, Brach J, Tellin W, Imbarlina F, Delitto A. Spinal palpation for lumbar segmental mobility and pain provocation: an interexaminer reliability study. Journal of Manipulative and Physiological Therapeutics 2008;31(6):465473.

Shacklock M. Clinical neurodynamics: a new system of musculoskeletal treatment. London: Elsevier; 2005.

Shah RV, Everett CR, McKenzie-Brown AM, Sehgal N. Discography as a diagnostic test for spinal pain: a systematic and narrative review. Pain Physician 2005;8:187-209.

Slater $\mathrm{H}$. The effect of foot and ankle positions on the response to the SLR test. In: Jones HM, Jones MA, Milde MR, editors. $6^{\text {th }}$ Biennial Conference of the Manipulative Physiotherapists Association of Australia. Adelaide: Manipulative Physiotherapists Association of Australia; 1989.p. 183-190.

Spiliopoulou I, Korovessis P, Konstantinou D, Dimitracopoulos G. IgG and IgM concentration in the prolapsed human intervertebral disc and sciatica etiology. Spine 1994;19(12):1320-1323.

Sterling M, Pedler A, Chan C, Puglisi M, Vuvan V, Vicenzino B. Cervical lateral glide increases nociceptive flexion reflex threshold but not pressure or thermal pain thresholds in chronic whiplash associated disorders: a pilot randomised controlled trial. Manual Therapy 2010;15:149-153.

Styf J. Entrapment of the superficial peroneal nerve: diagnosis and results of decompression. Journal of Bone and Joint Surgery 1989;71B:131-135.

Styf J, Korner I. Chronic anterior compartment syndrome of the leg. Journal of Bone and Joint Surgery American Edition 1986;68:1338-1347.

Tanaka N, Fujimoto Y, An HS, Ikuta Y, Yasuda M. The anatomic relation among the nerve roots, intervertebral foramina and intervertebral discs of the cervical spine. Spine 2000;25(3):286-290.

Uziel Y, Hashkes P. Growing pains in children. Pediatric Rheumatology 2007;5(5):1-4. doi:10.1186/1546-0096-5-5 (last accessed 29th September 2009). 
Figure1. Body chart and symptom behaviour.

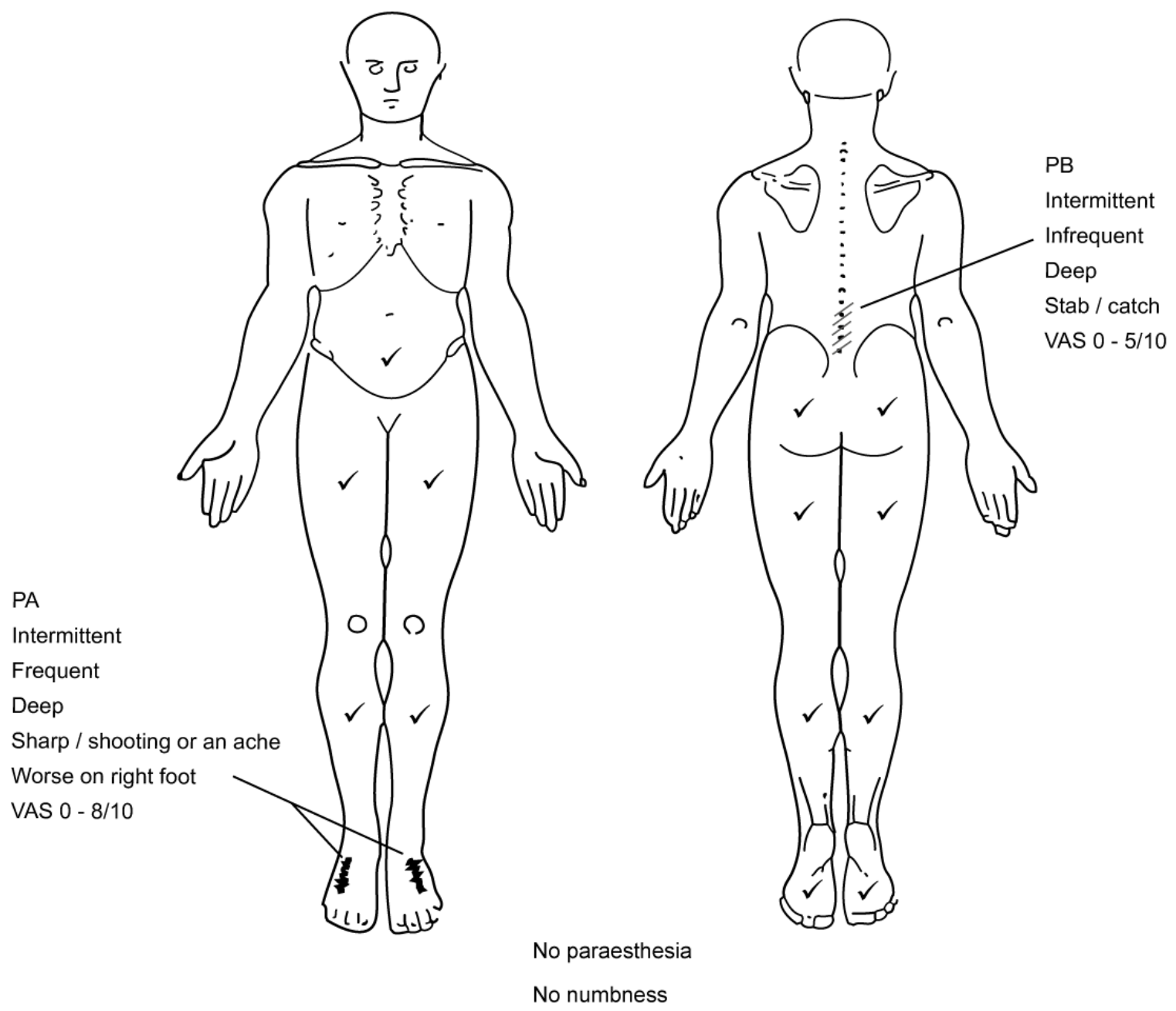


Table 1. Summary of outcome measures on first and last physiotherapy sessions.

\begin{tabular}{lll}
\hline Outcome Measure & Session 1 & Session 17 \\
\hline $\begin{array}{l}\text { VAS score for worst foot pain } \\
\text { during most recent tennis } \\
\text { training session }\end{array}$ & $8 / 10$ & pain-free \\
\hline $\begin{array}{l}\text { Range of SLR with } \\
\text { plantarflexion/inversion to } \\
\text { onset of pain }\end{array}$ & right: $35^{\circ}$ foot pain & right: $65^{\circ}$ pain-free \\
\hline $\begin{array}{l}\text { Range of knee extension } 40^{\circ} \text { foot pain } \\
\text { during slump testing with } \\
\text { plantarflexion/inversion to } \\
\text { onset of pain }\end{array}$ & $\begin{array}{l}\text { right: }-40^{\circ} \text { knee extension, } \\
\text { foot pain }\end{array}$ & $\begin{array}{l}\text { right: }-20^{\circ} \text { knee extension, } \\
\text { pain-free }\end{array}$ \\
\hline $\begin{array}{l}\text { left: }-40^{\circ} \text { knee extension, } \\
\text { foot pain }\end{array}$ & $\begin{array}{l}\text { left: }-20^{\circ} \text { knee extension, } \\
\text { pain-free }\end{array}$ \\
$\begin{array}{l}\text { VAS score for foot pain after } \\
1 \text { minute of running on toes }\end{array}$ & $3 / 10$ & pain-free \\
\hline
\end{tabular}

VAS: visual analogue scale.

SLR: straight leg raise. 
Table 2. Description of treatment.

\begin{tabular}{|c|c|}
\hline Session & Intervention \\
\hline $\begin{array}{l}\text { Session } 1 \\
(\text { day } 1)\end{array}$ & $\begin{array}{l}\text { - Patient evaluation and data collection } \\
\text { - Patient education - clinical diagnosis } \\
\text { - postural correction in sitting } \\
\text { - postures/activities to avoid } \\
\text { - tennis training sessions reduced to } 3 \text { times weekly (9 hours) }\end{array}$ \\
\hline $\begin{array}{l}\text { Session } 2-4 \\
\text { (day } 4,8 \text { and } 11)\end{array}$ & $\begin{array}{l}\text { - Neural mobilization - supine with towel roll under lumbar spine, right SLR with } \\
\text { plantarflexion/inversion to just prior to pain provocation (5 sets of } 20 \text { repetitions) }\end{array}$ \\
\hline $\begin{array}{l}\text { Session } 5 \\
\text { (day 15) }\end{array}$ & $\begin{array}{l}\text { - } \quad \text { Neural mobilization - as previous session } \\
\text { extension with plantarflexion/inversion to just prior to symptom reproduction ( } 2 \text { sets } \\
\text { of } 20 \text { repetitions twice daily) }\end{array}$ \\
\hline $\begin{array}{l}\text { Session } 6-9 \\
\text { (day 18, 22, } 25 \text { and 29) }\end{array}$ & $\begin{array}{l}\text { - Neural mobilization - as previous session increased to } 5 \text { sets of } 30 \text { repetitions } \\
\text { - Home exercise program -second home exercise added, extension in standing (10 } \\
\text { repetitions) intermittently during day to break up prolonged sitting }\end{array}$ \\
\hline $\begin{array}{l}\text { Session } 10 \text { and } 11 \\
\text { (day } 32 \text { and } 36 \text { ) }\end{array}$ & $\begin{array}{l}\text { - Neural mobilization - supine with towel roll under lumbar spine, left SLR with } \\
\text { plantarflexion/inversion to just prior to pain provocation ( } 5 \text { sets of } 20 \text { repetitions) }\end{array}$ \\
\hline $\begin{array}{l}\text { Session } 12 \text { and } 13 \\
\text { (day } 39 \text { and } 43 \text { ) }\end{array}$ & $\begin{array}{l}\text { - L2/3 left unilateral PA mobilizations (grade } \mathrm{III}^{-} \text {) in prone with left leg positioned just } \\
\text { prior to pain provocation, in SLR with mid range plantarflexion } \\
\text { ( } 6 \text { sets of } 1 \text { minute) }\end{array}$ \\
\hline $\begin{array}{l}\text { Session } 14 \\
\text { (day } 50)\end{array}$ & $\begin{array}{l}\text { - } \quad \text { L2/3 left unilateral PA mobilizations as previous session except grade III } \\
\text { - } \quad \text { Patient education - tennis training sessions increased to } 4 \text { times weekly (13 hours) }\end{array}$ \\
\hline $\begin{array}{l}\text { Session } 15 \text { and } 16 \\
\text { (day } 57 \text { and 64) }\end{array}$ & $\begin{array}{l}\text { - L2/3 left unilateral PA mobilizations as previous session except foot positioned in } \\
\text { end range plantarflexion } \\
\text { - Patient education - tennis training increased to full weekly schedule (15 hours) } \\
\text { - stop right neural mobilization home exercise } \\
\text { - continue extension in standing exercise to break up prolonged } \\
\text { sitting } \\
\text { - future back care }\end{array}$ \\
\hline
\end{tabular}

SLR: straight leg raise.

PA: postero-anterior. 